\title{
FEMINICÍDIO, TECNOLOGIA DE GÊNERO E ESCRITURA FEMININA NA OBRA GAROTAS MORTAS, DE SELVA ALMADA
}

\section{FEMINICIDE, GENDER TECHNOLOGY AND FEMALE SCRIPTURE IN THE WORK GAROTAS MORTAS, OF SELVA ALMADA}

\author{
Shaianna da Costa Araújo ${ }^{1}$ \\ [https://orcid.org/0000-0002-9658-7509] \\ Algemira de Macêdo Mendes² \\ [https://orcid.org/0000-0002-9253-7088] \\ DOI: 10.30612/raido.v14i35.12166
}

RESUMO: Neste artigo propomos conduzir uma análise da obra literária Garotas Mortas (2018), de autoria da escritora argentina Selva Almada. A partir das narrativas imbricadas na obra, empreenderemos discussôes acerca do feminicídio e de suas raízes históricas e culturais, recorrendo, para tanto, aos estudos feministas promovidos por Perrot (2007) e Muraro (1997). Estabelecendo diálogos com as proposiçôes de Cixous (2017), identificaremos a obra analisada como manifestaçăo da escritura feminina, posto que constrói espaços para a reverberaçăo de vozes até entâo silenciadas e prega a emancipaçăo do corpo feminino. Traçaremos relaçóes, ainda, entre corpo feminino, gênero, feminicídio e política.

Palavras-Chave: Garotas Mortas. Feminicídio. Feminismo. Tecnologia de gênero.

ABSTRACT: In this paper we propose to conduct an analysis of the literary work Garotas Mortas (2018), written by Argentine Selva Almada. From the narratives imbricated in the work, we will undertake discussions about feminicide from its historical and cultural roots, using, to this end, the feminist studies promoted by Perrot (2007) and Muraro (1997). Establishing dialogues with the propositions of Cixous (2017), we will identify the work analyzed as a manifestation of female scripture, since it builds spaces for the reverberation of voices until then silenced and preaches the emancipation of the female body. We will also draw relationships between female body, gender, feminicide and politics.

Keywords: Garotas Mortas. Feminicide. Feminism.Gender Technology.

Pós-graduada em Comunicaçâo Organizacional pela Universidade Estácio de Sá. Mestranda em Letras pela Universidade Estadual do Piauí.

2 Doutorado em Letras pela Pontifícia Universidade Católica do Rio Grande do Sul (2006), com estágio de doutorado sanduíche em Coimbra-PT (2005). Pós-doutora em Literaturas Africanas de Língua Portuguesa pela Universidade de Lisboa. Professora Associada da Universidade Estadual do Piauí/Universidade Estadual do Maranhâo,atuando na Graduaçăo e no Mestrado em Letras. 


\section{INTRODUÇÃO}

A obra literária Garotas Mortas (2018), da escritora Selva Almada, focaliza três casos reais de feminicídio registrados na Argentina, na década de 1980. A partir de reflexóes sobre política e gênero, Almada estabelece conexōes entre as mortes das jovens Andrea Danne, de 19 anos, María Luisa Quevedo, de 15 anos, e Sarita Mundín, de 20 anos - importante destacar que os restos mor cionamos, é uma obra que reúne características próprias do texto jornalístico, em decorrência do marcante cunho documental que permeia todo o trabalho e das atividades investigativas promovidas pela autora.

Apesar de dar destaque a esses três casos específicos, a obra é prolífica em narrativas diversas que abordam a violência de gênero, demonstrando a vulnerabilidade da condiçăo feminina em uma sociedade fortemente marcada pelos regimes autoritários, pela tradiçăo patriarcal e pelo conservadorismo: um contexto em que o corpo das mulheres e meninas ainda é compreendido como propriedade.

Neste artigo, pretendemos analisar a obra Garotas Mortas à luz das discussóes sobre relaçóes de gênero na literatura, demonstrando que o livro de Selva Almada trouxe importantes contribuiçóes para o movimento feminista, em especial no que diz respeito ao enfrentamento à cultura do feminicídio. Para tanto, recorreremos inicialmente aos estudos feministas que abordam o processo de construçâo do patriarcado, passando pela história do próprio feminismo. Em seguida, situaremos Garotas Mortas no campo da escritura feminina, revelando as conexóes entre literatura e corpo, a partir das discussóes empreendidas por Cixous (2017) em seu manifesto poético-teórico. Pretendemos, ainda, provar que a obra analisada identifica o corpo feminino como objeto de disputa política, à medida em que localizarmos pontos de convergência com a obra de Davis (2017) e com os conceitos propostos por Lauretis (1994) acerca da tecnologia de gênero.

\section{MEU CORPO, REGRAS DELES: 0 FEMINICÍDIO E A PROPRIEDADE PRIVADA}

Os casos relatados em Garotas Mortas foram registrados na década de 1980 - como observa a própria autora, quando na Argentina "ainda se ignorava o termo feminicídio". Por isso, năo faremos uso desse termo em seu sentido puramente jurídico, já que, naquele país, o assassinato de uma mulher pelo fato de ser mulher só foi tipificado no Código Penal em 2012. Originalmente, o termo foi difundido em 1976, pela socióloga sul-africana Diane E. H. Russel, perante o Tribunal Internacional Sobre Crimes Contra as Mulheres. Meneghel e Portella (2017) esmiúçam as proposiçōes de Russel, esclarecendo que o feminicídio (ou femicídio) pode ser definido como

\footnotetext{
(...) terrorismo sexual ou genocídio de mulheres. O conceito descreve o assassinato de mulheres por homens motivados pelo ódio, desprezo, prazer ou sentimento de propriedade. Russel ancora-se na perspectiva da desigualdade de poder entre homens e mulheres, que confere aos primeiros o senso de entitlement - a crença de que lhes é assegurado o direito de dominaçáo nas relaçóes com as mulheres tanto no âmbito da intimidade quanto na vida pública social - que, por sua vez, autoriza o uso da violência, inclusive a letal, para fazer valer sua vontade sobre elas. (MENEGHEL, PORTELLA, 2017, p. 3079)
} 
Em Garotas Mortas, Almada ratifica essa definiçăo, reconhecendo ainda que o feminicídio é o ponto culminante do continuum da violência - seja física ou moral contra as mulheres. Vejamos:

Eu náo sabia que uma mulher podia ser morta pelo simples fato de ser mulher, mas tinha escutado histórias que, com o tempo, fui ligando umas às outras. Casos que năo terminavam com a morte da mulher, mas em que ela era objeto da misoginia, do abuso, do desprezo. (ALMADA, 2018, p. 13)

É a partir dos estudos sobre a história das mulheres e do feminismo que podemos compreender como a cultura patriarcal, para a qual as mulheres săo meras propriedades, foi criada e difundida, e como essa cultura opressiva ainda se sustenta nos dias atuais. Muraro (1997) analisa a evoluçáo das sociedades humanas, partindo das comunidades primitivas, nas quais o trabalho se reduzia à coleta e à caça de pequenos animais. Nesses grupamentos, a força física năo era considerada fator de preponderância, e as mulheres eram vistas como seres sagrados, por conta da capacidade de engravidar. É durante o neolítico que os homens descobrem que também possuem um papel fundamental na procriaçăo, e assim começam a dominar a sexualidade feminina. Em seguida, com o desenvolvimento da agricultura e o consequente surgimento da propriedade privada, o controle social e individual do homem sobre o corpo feminino se intensifica.

Aparece entăo o casamento como o conhecemos hoje, em que a mulher é propriedade do homem e a herança se transmite através da descendência masculina. (...) As mulheres tinham sua sexualidade rigidamente controlada pelos homens. 0 casamento era monogâmico e a mulher era obrigada a sair virgem das máos do pai para as măos do marido. Qualquer ruptura desta norma podia significar a morte. (MURARO, 1997, p.7)

Em Garotas Mortas, deparamo-nos com a representaçăo literária da perpetuaçáo dessa cultura de posse e dominaçáo que escraviza o corpo das mulheres, embora ela se manifeste de formas diferentes - e ainda assim, terrivelmente familiares - em épocas mais recentes.

Essas cenas conviviam com outras menos chamativas: a măe de uma amiga que năo se maquiava porque o marido năo deixava. Uma colega de trabalho da minha máe que todo mês entregava o salário inteiro ao marido, para que ele o administrasse. Outra que năo podia visitar a família porque o marido achava que os parentes dela náo tinham nível. Outra que era proibida de usar sapatos de salto alto porque isso era coisa de puta. (ALMADA, 2018, p. 37)

Perrot (2007), em seu estudo sobre a história das mulheres, confirma que o casamento, inicialmente concebido como aliança contratual e náo como celebraçáo do amor, relega as mulheres a uma posiçáo de subalternidade. Destacamos aqui que as mulheres sequer eram partícipes desse "contrato", já que esse termo pressupōe uma certa equidade entre os interessados; as mulheres, porém, eram "transmitidas" como meros objetos. $O$ papel de sujeito possuidor cabia ao homem, que concentrava diversos "direitos", inclusive - e principalmente - sobre o corpo da companheira.

A mulher casada é, ao mesmo tempo, dependente e dona-de-casa. (...) Dependente em seu corpo, ele pode receber "corretivos", como uma criança indócil, pelo chefe da 
casa, depositário da ordem doméstica. "Quem ama castiga." Bater na mulher é uma prática tolerada, admitida, desde que náo seja excessiva. Se os vizinhos escutam os gritos de uma mulher maltratada, năo interferem. "O homem deve ser rei em sua casa." (PERROT, 2007, pp. 47-48)

Pretendemos demonstrar até aqui que a história da violência contra as mulheres - sendo que o feminicídio é o episódio culminante de um processo de degradaçáo e subjugaçăo - é a história de apropriaçâo do corpo da mulher pelo homem, por meio das instituiçōes criadas para sustentar uma sociedade baseada na propriedade privada. Em Garotas Mortas, Selva Almada explora essa premissa, trabalhando narrativas que representam o perigo inerente à condiçâo de ser mulher ou menina. A obra literária nos ajuda a compreender que o assassinato de mulheres é uma prática sistemática, nâo restrita aos casos isolados ou à obra do azar, mas sim o produto de um longo processo de socializaçăo patriarcal.

Tanto é que, embora Almada discorra acerca das experiências vividas pelas mulheres no seio do casamento - tal como citamos acima - os três casos efetivamente investigados por ela se referem a garotas muito jovens, náo inseridas no contexto marital. Entre as três protagonistas, apenas Sarita Mundín havia passado por um casamento: uma relaçăo em que o homem, nâo por coincidência, achou-se no direito de controlar e explorar o seu corpo, obrigando-a a se prostituir para sustentar a casa.

Recorrendo aos aportes teóricos aqui colocados, deduzimos que cada uma das três Garotas Mortas de Almada representa uma faceta diferente do terror vivido diariamente pelas mulheres e meninas. Logo no início da obra, a autora relata seu primeiro contato com a história de Andrea Danne, morta em sua própria residência, enquanto dormia, com uma punhalada no coraçâo.

Eu tinha treze anos e, naquela manhá, a notícia da garota morta me chegou como uma revelaçăo. Minha casa, a casa de qualquer adolescente, năo era o lugar mais seguro do mundo. Você podia ser morta dentro da sua própria casa. O horror podia viver sob o mesmo teto. (ALMADA, 2018, p. 12)

Almada se vale do caso de Andrea para desmistificar a noçăo de que "o perigo está lá fora", demonstrando como a educaçấo castradora e moralista reservada às meninas pode ser hipócrita.

Os estupradores eram sempre homens desconhecidos que agarravam uma mulher e a levavam para o mato, ou que entravam em sua casa forçando uma porta. Desde pequenas nos ensinavam que năo devíamos falar com estranhos e que devíamos tomar cuidado com o Tarado. (...) Nunca ninguém falou que você podia ser estuprada pelo marido, pelo pai, pelo irmáo, pelo vizinho, pelo professor. Por um homem em quem você tem toda a confiança. (ALMADA, 2018, p. 36-37)

Já o caso de María Luisa Quevedo, de apenas 15 anos, representa a naturalizaçăo do abuso sexual e do feminicídio, demonstrando como uma comunidade pode trabalhar de forma integrada e inconsciente para acobertar esse tipo de violência, principalmente se os homens suspeitos pertencerem a círculos de poder político e financeiro. María Luisa saiu de casa para cumprir sua jornada como empregada doméstica em casa de família, na cidade de Presidencia Roque Sáenz Peña, em 08 de dezembro de 1983. Seu corpo foi encontrado três dias depois, violentado e estrangulado, num terreno baldio. Ninguém foi processado pelo assassinato. 
A história de Sarita Mundín remete a uma realidade talvez ainda mais cruel, por estar situada num contexto de miséria e prostituiçăo. Măe solteira, foi vítima da violência do ex-marido. Foi vista pela última vez ao sair com um de seus clientes, que havia assumido o papel de "protetor", passando a apresentar comportamentos possessivos e igualmente violentos.

Garotas Mortas apresenta em seu bojo várias outras narrativas que corroboram os efeitos nocivos da cultura que fez do corpo da mulher uma posse do homem, processo histórico advindo desde os primórdios das comunidades humanas e que se perpetua até a atualidade. A adolescente sucessivamente estuprada por dois amigos de um pretendente frustrado, como vingança contra "essas vadias que sempre tiram o cu da reta" (p.); a garota morta a facadas pelo ex-namorado obsessivo que năo aceitava o fim do relacionamento; o medo que a própria autora relata ter sentido, ao ser assediada por um homem que lhe deu carona.

Embora a violência de gênero, sobretudo no âmbito da família, tenha passado a ser legalmente condenável na sociedade ocidental - na América Latina, até bem recentemente - ainda săo generalizadas as práticas que igualam mulheres a objetos, fator que confere aos homens o poder de controlar o corpo, a vida e a morte de mulheres e meninas, tal qual nos alerta a obra Garotas Mortas.

Alves e Pitanguy (1982) concordam que a perseguiçâo ao corpo das mulheres teve início com a formaçáo e o triunfo do tabu sexual, para o qual o corpo feminino é uma fonte de malefícios. Muraro (1997) corrobora essa constataçấo, relacionando a demonizaçáo do corpo, também, à sistematizaçấo do trabalho: o sexo e o prazer passam a representar o pecado, porque tornou-se necessário domesticar os corpos para as penúrias e as exigências de uma sociedade industrializada.

O genocídio das "bruxas" na Idade Média, assim como os numerosos feminicídios registrados na contemporaneidade, foi justificado e estimulado por essa cultura de perseguiçăo ao corpo feminino. Alves e Pitanguy (1982) observam que năo era propriamente a feitiçaria que os inquisidores pretendiam extirpar no fogo, mas sim a própria condiçăo feminina. Do mesmo modo, năo é o adultério ou a "desobediência" o que os agressores da atualidade pretendem aniquilar, mas sim a capacidade das mulheres de se colocarem como sujeitos emancipados e dotados de vontade.

\section{GAROTAS MORTAS: A ESCRITURA FEMININA COMO FERRAMENTA DE REAPROPRIAÇÃO DO CORPO}

Vimos no tópico anterior que Garotas Mortas aborda as diferentes facetas da violência perpetrada contra as mulheres, mostrando que o feminicídio - ou o sistemático assassinato de mulheres por questôes de gênero - é o produto de uma cultura do medo, que coloca o homem no papel de possuidor e a mulher como um objeto a ser domado e possuído. Compreendemos como a história e as instituiçóes sociais muitas vezes legitimaram a violência contra as mulheres, com lastro nessa noçấo de propriedade.

Mas a obra Garotas Mortas, porém, ao tempo em que reconhece e denuncia a existência de um sistema político-ideológico que aprisiona e violenta o corpo das mulheres, cumpre seu papel literário e social de ferramenta emancipadora, inspirando ao movimento, à libertaçâo da escritura feminina. Como interpela Cixous: 
É preciso que a mulher se escreva: que a mulher escreva sobre mulher e traga as mulheres à escrita, de onde elas foram tăo violentamente distanciadas quanto foram de seus corpos; pelas mesmas razóes, pela mesma lei, com a mesma letal finalidade. A mulher precisa se colocar no texto - como no mundo, e na história -, através de seu próprio movimento. (CIXOUS, 2017, p. 129)

Garotas Mortas é um emblemático exemplo de escritura feminina que fala pelas mulheres, e que fala de mulheres para mulheres e para o resto do mundo. Além de se identificar, ela mesma, como voz feminina e potencial vítima da violência retratada nas histórias que narra, Almada traz para a literatura - mais um dos campos de disputa social há tanto tempo dominado pelos homens - as vozes dessas meninas e mulheres que foram desapropriadas de seus corpos e de suas vidas.

Talvez seja esta a sua missăo: recolher os ossos das garotas, armá-las, dar-lhes voz e depois deixa-las correr livremente para onde tiverem que ir. (ALMADA, 2018, p. 34)

Cixous (2017) nos instiga a refletir acerca do problema de uma escritura feminina, sobre a necessidade de que os textos carreguem, sim, as marcas da mulher e da sua sexualidade. Para ela, as escrituras săo características, fato que viabiliza a existência de uma literatura masculina necessariamente opressora, e que, por năo se reconhecer e nâo se proclamar como tal, mascara a subjugaçâo das mulheres com os adornos da ficçăo e com convicçóes sociais amplamente aceitas, ocultadas e reproduzidas.

A emancipaçáo do corpo e da escritura feminina passa pelo processo de reapropriaçáo da sexualidade, dos territórios mantidos sob sigilo, por meio da relaçáo des-censurada da mulher com suas próprias forças. Cixous dialoga com Almada ao lembrar que as mulheres geralmente sâo relegadas às sombras da culpa, impedidas de conhecer e explorar o próprio corpo.

(...) culpada de tudo, todas as vezes: de ter desejos, de năo ter; de ser frígida, se ser "quente" demais; de náo ser os dois ao mesmo tempo; de ser demasiadamente măe ou nâo o suficiente; de ter filhos e de náo ter; de amamentar e de náo amamentar... (CIXOUS, 2017, p. 136)

Em Garotas Mortas, Almada também discute a questâo da "culpa" sempre atribuída às mulheres, inclusive nos casos em que elas sâo vítimas.

No entanto, naquela semana curta e intensa que marcou sua saída de casa para começar a circular no mundo adulto, o mundo do trabalho fora de casa, María Luisa fez duas amigas: Norma Romero e Elena Taborda, duas moças um pouco mais velhas que ela e mais vividas. Quevedo lhes atribui a culpa de levá-la para o mau caminho. Como se a morte fosse um castigo por algo de errado que ela andava fazendo. (ALMADA, 2018, p. 68)

A culpa é um sentimento que persegue a condiçăo feminina, sobretudo no que diz respeito à relaçâo da mulher com seu próprio corpo. A violaçăo e a morte sấo representadas como meras consequências da falta de cuidado ou de pudor das vítimas. Essas impressóes, de acordo com nossos estudos, também advêm de uma educaçăo castradora, que busca ensinar as meninas a se protegerem e a negarem sua sexualidade. Beauvoir (2009) empreendeu diversas reflexóes acerca da alienaçâo entre mulher e corpo/sexo, inclusive discorrendo acerca do sentimento de culpa que é introjetado no espírito da jovem em formaçăo. 
Essas condutas traduzem muitas vezes um nojo pelo desejo sexual, um sentimento de culpa: se tenho tais pensamentos, tais apetites, nâo valho mais do que uma prostituta, sou uma prostituta, pensa a jovem. (BEAUVOIR, 2009, p. 464)

O nojo pelo corpo feminino está na base da misoginia instituída desde o estabelecimento do tabu sexual, e a misoginia, por sua vez, é o sentimento que está na base da cultura do feminicídio. Se a culpa persegue as mulheres no decorrer das suas vidas - e até depois da morte, como notamos em Garotas Mortas - a máe, como símbolo maior da condiçâo feminina no sistema patriarcal, carrega um fardo ainda mais pesado, em decorrência da forçada aureola de "amor" e "candura" que foi colocada sobre a maternidade. Para Perrot (2007), a funçáo materna é um dos pilares do Estado moderno, e por isso se constitui como fato social, de modo que o controle do corpo e das açóes das mâes, bem como da natalidade, tornou-se objeto de atuaçăo política. A măe é ainda mais vulnerável aos julgamentos sociais. Em Garotas Mortas, Almada se vale da figura da mâe da Andrea Danne para trazer à tona mais essa discussâo sobre gênero:

Essa imagem horrorizava a todos: uma măe a quem aconteceu o pior que pode acontecer a uma mâe sentando-se na cadeira do salāo de beleza. Esse gesto, que também poderia ser entendido como uma tentativa de se distrair do pesadelo que estava vivendo, foi logo interpretado como um sinal de culpa. De uma mâe que tem a filha assassinada esperamos, ao que parece, que arranque os cabelos, que chore desesperadamente, que agite o punho em riste pedindo vingança. Năo suportamos a calma. Năo perdoamos a resignaçăo. (ALMADA, 2018, p. 80) (grifo nosso)

Cixous propóe a recuperaçấo da figura da măe, o rompimento do discurso masculino em que ela se engendrou. Para ela, a mulher deve se reapropriar como um corpo sem fim, uma doadora que provê sem se aniquilar ou tomar, sem se constituir, como professa a psicanálise, apenas como falta, inveja, recalque e carência. Se, para Cixous, a escritura feminina é uma forma de emancipaçáo do corpo das mulheres, a escritura que foi relegada às mulheres ao longo dos últimos séculos é marcada pela culpa e pela vergonha: é a redaçấo confessional, verificada nos diários secretos. Alerta Cixous:

Aliás, escreveste um pouco, porém às escondidas. Isso nâo é bom, mas porque era escondido, tu te punias por escrever, e năo ias até o fim; ou, ao escrever, irresistivelmente, como nos masturbamos às escondidas, nâo era para ir mais longe, mas para amenizar um pouco a tensăo, apenas o suficiente para que o demasiado cessasse de atormentar. E, em seguida, logo que gozamos, nos precipitamos a nos culpabilizar - para se fazer perdoar -; ou a esquecer, a enterrar, até a próxima. (CIXOUS, 2017, p. 131)

Tanto Perrot (2007) quanto Beauvoir (2009) confirmam que a escritura das mulheres ficava restrita ao domínio privado. As mulheres, por terem sido relegadas ao ambiente doméstico, existiam fora do espaço público. Seus diários íntimos, que săo a um tempo retratos da solidâo e consubstanciaçâo da culpa, destinavam-se ao fogo ou ao esquecimento, a mesma aniquilaçâo reservada aos seus corpos. As correspondências, os diários e as autobiografias năo săo gêneros femininos por excelência, "mas se tornaram mais adequados às mulheres justamente por seu caráter privado" (PERROT, 2007, p. 28). Existem, porém, poucas autobiografias de mulheres publicadas; isso porque as meninas foram ensinadas que suas vidas náo significam nada, ou, como 
nos lembra Cixous, imaginam que a escrita é reservada aos "grandes-homens": Perrot revela, aliás, que correspondências femininas privadas raramente eram publicadas, a menos quando punham em cena esses tais "grandes-homens". Importante mencionar aqui o fenômeno das mulheres que se publicavam sob pseudônimos masculinos, a exemplo de George Sand.

Por isso, destacamos aqui a obra Garotas Mortas como exemplar de uma escritura feminina emancipadora, que dá voz e valor a essas vidas que se extinguiram sem nada representar para o sistema social, político e jurídico que foi construído sobre a demonizaçấo do corpo feminino, sobre a pedagogia da culpa e sobre a violência contra as mulheres. A obra literária em comento, mais que revelar o horror contido em crimes específicos, questiona toda a estrutura que possibilitou o estabelecimento da misoginia enquanto componente naturalizado da sociedade atual. Cixous nos ensina que "um texto feminino nâo pode deixar de ser mais do que subversivo" (CIXOUS, 2017, p. 147). Garotas Mortas carrega em seu bojo essa subversăo, posto que rompe a herança do silêncio (MOREIRA ALVES e PITANGUY, 1982, p. 11) que assombra a história das mulheres.

\section{TECNOLOGIA DE GÊNERO, POLÍTICA E FEMINICÍDIO}

A leitura de Garotas Mortas nos instiga a pensar em violência de gênero e na condiçăo feminina. De fato, já falamos bastante em violência contra a "mulher", e faz-se necessário descobrir que entidade é essa tăo cruelmente violentada pelo sistema patriarcal. De onde vieram as características que tornaram a mulher suscetível a ser objeto da violência e do desprezo? A repetiçăo da história e os numerosos feminicídios registrados desde os primórdios da humanidade nos provam que a subjugaçâo da mulher é produto de um destino biológico irreversível? Os estudos feministas das últimas décadas questionam justamente o que batizaram de "reducionismo biológico", que acarreta a universalizaçâo das mulheres - ou seja, produz uma concepçâo genérica de mulher.

Para Lauretis (1994), o gênero é um fator imaginário que se inclui na diferenciaçăo sexual como efeito de linguagem. O gênero náo é uma condiçáo natural, mas sim a representaçâo das relaçôes sociais: o pertencimento a uma classe, a uma categoria, de forma que se atribuam ao indivíduo características que năo eram previamente conhecidas.

Se as representaçóes de gênero săo posiçóes sociais que trazem consigo significados diferenciais, entăo o fato de alguém ser representado ou se representar como masculino ou feminino subentende a totalidade daqueles atributos sociais. (LAURETIS, 1994, p. 212)

O gênero é um atributo socialmente construído, por meio da ideologia, produzindo diferenças sexuais que năo existem no mundo natural. Os atributos sociais mencionados por Lauretis se traduzem nos estereótipos destinados às mulheres: a docilidade, a passividade, a subordinaçâo. A escritora contemporânea Chimamanda Ngozi Adichie também questiona o reducionismo biológico:

Meninos e meninas sâo inegavelmente diferentes em termos biológicos, mas a socializaçáo exagera essas diferenças. (...) Como a questáo de gênero incomoda, as 
pessoas recorrem a vários argumentos para cortar a conversa. Algumas lançam máo da biologia evolutiva dos macacos, lembrando como as fêmeas, por exemplo, se curvam perante os machos. Mas a questăo é a seguinte: nós năo somos macacos. Macacos vivem em árvores e comem minhocas. Nós, năo. (ADICHIE, 2015, pp. 12-14)

Esses arquétipos de passividade e subordinaçăo permeiam o imaginário coletivo e permitiram que as mulheres fossem identificadas como objetos de posse, destituídos de vontade. É importante destacar, porém, que, embora as categorias de masculinidade e feminilidade tenham sido ideologicamente produzidas, essa divisăo resulta em consequências no mundo real - e o assassinato sistemático de mulheres é uma delas.

Em Garotas Mortas, Selva Almada também discorre sobre a relaçâo entre a generalizaçăo das mulheres e o feminicídio. Já que a sociedade entende que todas as mulheres devem reunir determinados atributos, todas as mulheres estâo sujeitas à mesma violência: todas as garotas săo a mesma garota, e apenas o acaso separa algumas da morte. Por isso, é tăo importante compreender o feminicídio como problema social advindo de um processo histórico.

Faz um mês que o ano começou. Pelo menos dez mulheres foram assassinadas por serem mulheres. Digo pelo menos porque esses săo os nomes que apareceram nos jornais, daquelas que viraram notícia. (...) Estamos no verăo e faz calor, quase tanto quanto naquela manhă de 16 de novembro de 1986, quando, de certo modo, este livro começou a ser escrito, quando a garota morta atravessou meu caminho. Agora estou com quarenta anos e, diferentemente dela e dos milhares de mulheres assassinadas em nosso país de lá para cá, continuo viva. Apenas uma questăo de sorte. (ALMADA, 2018, p. 121)

Davis (2017) chama atençâo para o fato de que praticamente todas as mulheres podem recuperar em suas memórias, desde a infância, episódios de assédio e abuso. Ressalta, ainda, que a violência vivida individualmente pelas mulheres deve ser situada no contexto sociopolítico mais amplo, porque a violência de gênero é eivada de mediaçōes sociais.

Essas manifestaçóes específicas de violência contra a mulher se situam em um espectro mais amplo de violência produzida socialmente, que inclui violaçóes sistemáticas orquestradas contra os direitos econômicos e políticos femininos. (DAVIS, 2017, p. 42)

O contexto de Garotas Mortas - a Argentina da década de 1980 - tal como explicitado na obra, denota a situação de um país recém-saído de uma das ditaduras mais sanguinolentas de sua história. E as ditaduras sâo justamente caracterizadas pela sistemática violaçăo aos direitos humanos, sendo que as mulheres, sobretudo as pobres, săo particularmente vulneráveis a essas investidas. Embora o regime de sete anos tenha terminado com a eleiçâo de um novo presidente em 11 de dezembro de 1983, mesmo dia em que o corpo de María Luisa Quevedo foi encontrado - e é imprescindível destacar que Selva Almada faz questăo de registrar esse fato na obra - os efeitos de uma ditadura e a cultura produzida em torno dela tendem a permanecer por muito tempo nas malhas das relaçôes sociais. 


\section{CONSIDERAÇÕES FINAIS}

Garotas Mortas é uma obra literária que cumpre seu papel social, inspirando o movimento e a açăo. Ao tempo em que nos lembra que ser mulher é ter medo, estimula ao rompimento da rede de violência, por meio da denúncia consciente e da reflexâo sobre o problema de gênero. A obra de Selva Almada possui diversas camadas, igualmente complexas, e por isso suscita tantas discussōes.

Primeiro, aborda sem volteios a face mais crua da violência contra as mulheres, expondo realisticamente a misoginia contida na violaçăo do corpo feminino - como na história da adolescente atacada por dois rapazes que utilizaram até uma garrafa para estupra-la. Em seguida, Almada expóe as raízes históricas e culturais das múltiplas violências que culminam no feminicídio, ao discorrer sobre situaçôes em que mulheres săo tratadas como posses dos maridos e companheiros, que até mesmo as agridem continuamente, tudo com o conhecimento de comunidades que se mantém inertes. Somos, ainda, convidados pela autora a refletir sobre os contextos políticos que favorecem a violaçáo do corpo da mulher e a usurpaçáo de sua vida.

Embora dominada por imagens chocantes, a obra semeia mensagens de esperança, ao inscrever-se como símbolo do poder da escritura feminina, que é uma prodigiosa ferramenta para reapropriaçáo do corpo e da sexualidade, de modo que as mulheres possam romper os estereótipos de gênero que as relegaram ao papel de objetos possuídos. 


\section{REFERÊNCIAS}

ADICHIE, Chimamanda Ngozi. Sejamos todos feministas. Traduçăo de Christina Baum. Sâo Paulo: Companhia das Letras, 2015, 63 p.

ALMADA, Selva. Garotas Mortas. Săo Paulo: Todavia, 2018.

ALVES, Branca Moreira; PITANGUY, Jacqueline. 0 que é feminismo. Săo Paulo: Brasiliense, 1982. Coleçăo Primeiros Passos, n. 20.

BEAUVOIR, Simone de. O Segundo Sexo. Rio de Janeiro: Nova Fronteira, 2009.

CIXOUS, Hélène. O riso da Medusa. In: BRANDÁO, Isabel (Org.). Traduçóes da Cultura: Perspectivas Críticas Feministas. Florianópolis: EDUFAL, 2017. pp. 129-155.

DAVIS, Angela. Mulheres, cultura e política. Sáo Paulo: Boitempo, 2017.

DELAS.PT. Feminicídio na Argentina é "vingança contra as mulheres que năo se calam". Disponível em: https://www.delas.pt/feminicidio-na-argentina-e-vinganca-contra-as-mulheres-que-nao-se-calam/ Acesso em 23 jul. 2019.

LAURETIS, Teresa de. A tecnologia de gênero. In: HOLANDA, Heloisa Buarque de (Org.). Tendências e impasses: o feminismo como crítica cultural. Rio de Janeiro, Rocco, 1994. p. 206-242.

MENEGHEL, Stela Nazareth; PORTELLA, Ana Paula. Feminicídios: conceitos, tipos e cenários. In: Ciência \& Saúde Coletiva, 22 (9), pp. 3077-3086. Disponível em: http://www. scielo.br/pdf/csc/v22n9/1413-8123-csc-22-09-3077.pdf Acesso em 02 ago. 2019.

MURARO, Rose Marie. Breve Introduçâo Histórica. In: INSTITORIS, Heinrich. 0 martelo das feiticeiras. Rio de Janeiro: Record/Rosa dos Tempos, 1997, pp. 5-17.

PERROT, Michelle. Minha história das mulheres. Săo Paulo: Contexto, 2007.

Recebido em 30/05/2020

Aceito em 03/07/2020 